\title{
Central neurocytoma of spinal cord
}

\section{Neurocitoma central da medula espinhal}

\author{
Ricardo de Amoreira Gepp', Rogério Cirineu Sacco², Isabel Cristina Soares Brandão3, Eni Braga da Silveira³, \\ Altamir Monteiro Júnior ${ }^{3}$ \\ Sarah Network of Rehabilitation Hospitals, Brasília DF, Brazil. \\ ${ }^{1}$ Neurosurgery, Master in Science; \\ ${ }^{2}$ Neurosurgery; \\ ${ }^{3}$ Pathologic anatomy. \\ Correspondence: Ricardo de Amoreira Gepp; SQSW 300 Block M, 204; 70673-046 Brasília DF - Brasil; E-mails: ricardogepp@zipmail.com.br / rgepp@sarah.br \\ Conflict of interest: There is no conflict of interest to declare. \\ Received 02 August 2011; Received in final form 25 August 2011; Accepted 01 September 2011
}

Spinal cord neoplasms account for $4 \%$ of central nervous system (CNS) tumors ${ }^{1}$. Neurocytomas (CN) are neoplasms that occur in the ventricles, being rarely described in the spinal cord ${ }^{2}$. The clinical and neuropathological features of one $\mathrm{CN}$ are reported in this article. This is the first description of $\mathrm{CN}$ in the spinal cord in Brazil.

\section{CASE REPORT}

A 15-year-old woman had a right hand dysfunction and cervical pain. Magnetic resonance imaging (MRI) showed an intramedullary tumor. During surgery, it was observed a circumscribed lesion at the superior part of the tumor, infiltration in the inferior portion, and a subtotal resection was achieved. Patient kept the same neurological status after surgery.

Histopathological examination revealed sheets of uniform sized cells with small rounded nuclei, finely stippled chromatin, and inconspicuous nucleoli. The cytoplasm was scant, slightly eosinophilic. At some places, tumor cells showed clear perinuclear haloes resembling oligodendroglioma. There were cellular areas alternating with neuropil-like fibrillary matrix, often perivascular in orientation, resulting in a resemblance to ependymoma (Figure).

Immunohistochemical stains were performed and the following antibodies were used: glial fibrillary acidic protein (GFAP), epithelial membrane antigen (EMA), p53 protein, synaptophysin, S100 protein, vimentin, and Ki-67. The immunohistochemical showed strong and diffuse immunostainning for synaptophysin and S100 protein, expression of GFAP, and a high 13\% Ki-67 (Figure).

At the ultra-structural level, the neuropil-like matrix was revealed as a web of neuritic processes containing densecore granules, synaptic vesicles and bundles of microtubules, intermingled with astrocytic processes. Some synaptic junctions were also found. Cell bodies presented a round nucleus, with loose chromatin, and a scanty cytoplasm, with an evident granular endoplasmic reticulum, Golgi complex, microtubules, and some dense-core granules (Figure). These morphological and immunohistochemical findings indicate a neuronal differentiation, which is consistent with the diagnosis of $\mathrm{CN}$.

\section{DISCUSSION}

The World Health Organization (WHO) classification of CNS tumors includes CN since $1982^{2}$.

The differential diagnosis of $\mathrm{CN}$ includes oligodendroglioma and ependymoma ${ }^{2,3}$. The distinction from oligodendroglioma can only be made by immunohistochemical and ultra-structural evidence of neuronal origin seen in $\mathrm{CN}^{4}$. Ependymomas have a coarser glial fibrillary matrix, instead of the fine neuropil-like fibrillary matrix of $\mathrm{CN}$. Their cells exhibit more angulated nuclei, they are negative for synaptophysin and show at ultra-structural level true or intracytoplasmic lumens decorated by microvilli and cilia, which were not found in this case ${ }^{2,4}$. The occurrence of astrocytic differentiation is well documented in $\mathrm{CN}$, especially for extraventricular ${ }^{2,4}$. This was observed in the present case in the form of GFAP and S-100 protein expression and astrocytic processes ${ }^{4}$. The only feature observed that can be associated with an aggressive behavior was a high Ki-67 index ${ }^{3-5}$. Despite the absence of anaplastic features, labeling proliferative index in more than $2 \%$ is considered as this case atypical, according to Sharma et al. ${ }^{5}$.

This letter describes the tenth case of extraventricular $\mathrm{CN}$ on the spinal cord and is the first description of this tumor in Brazil. 

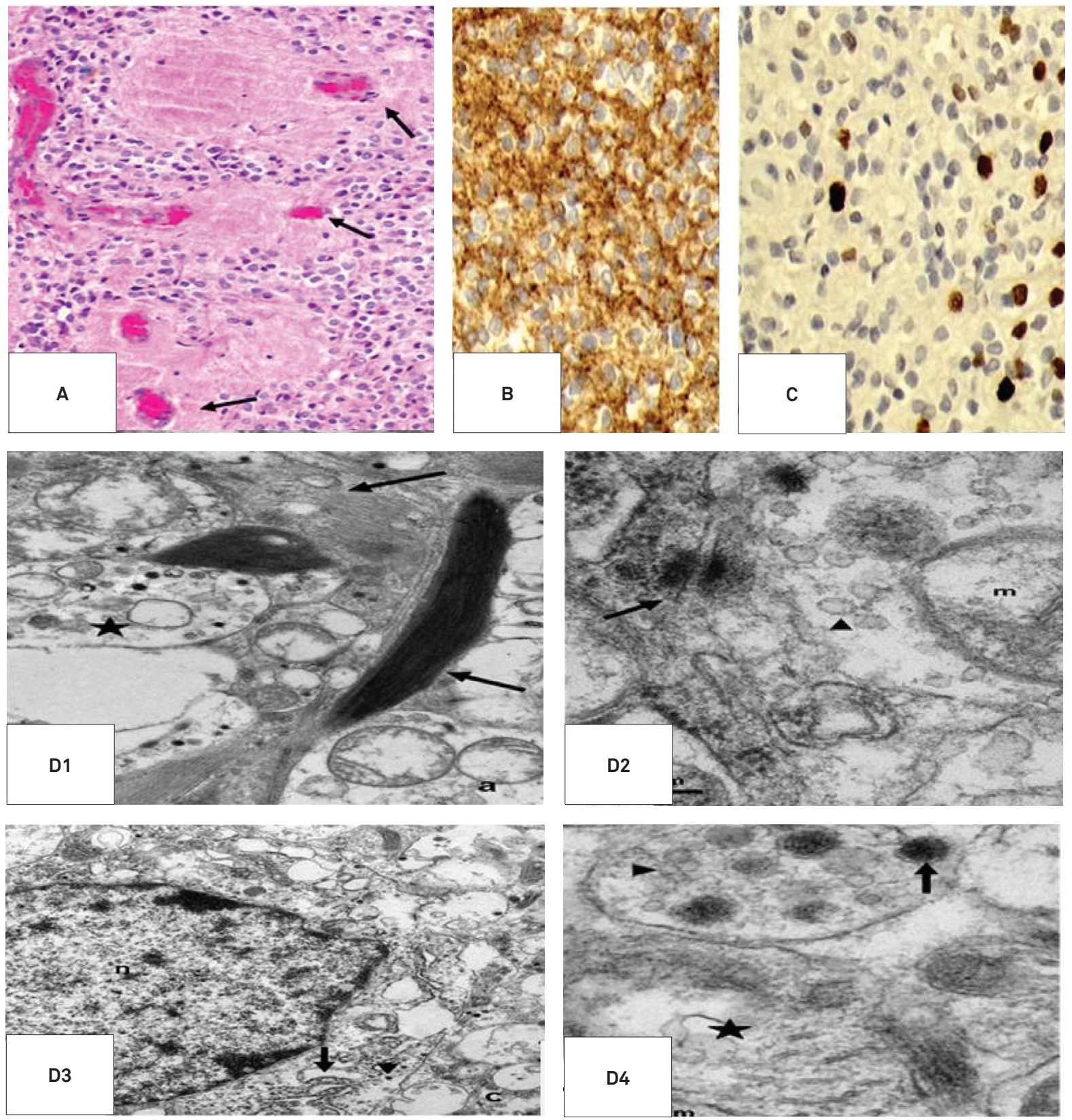

Figure. (A) Histopathology. Fibrillary matrix, perivascular in orientation (arrows), resembling perivascular pseudorosettes of ependymoma. (B) Immunohistochemistry. Strong and diffuse immunostainning for synaptophysin, indicating a neuronal differentiation. (C) High Ki-67. (D) Transmission of electron micrographs. (D1) Neuropil presenting neuritic processes containing dense-core granules (star) and astrocytic processes (arrows). (D2) Neuritic process presenting a synaptic junction (arrow), synaptic vesicles (arrowhead), and mitochondria (m). (D3) Cell body presenting a round nucleus (n), granular endoplasmic reticulum (arrow), and scattered dense-core granules (arrowhead). (D4) Detail of a neuritic process rich in microtubules (star) and another with dense-core granules (arrow) and synaptic vesicles (arrowhead).

\section{References}

1. Bouffet E, Pierre-Kahn A, Marchal JC, et al. Prognostic factors in pediatric spinal cord astrocytoma. Cancer 1998;83:2391-2399.

2. Sharma MC, Deb P,Sharma S, Sarkar C. Neurocytoma: a comprehensive review. Neurosurg Rev 2006;29:270-285.

3. Tatter SB, Borges LF, Louis DN. Central neurocytomas of the cervical spinal cord. Report of two cases. J Neurosurg 1994;81:288-293.
Hassoun J, Gambarelli D, Grisoli F, et al. Central neurocytoma. An electron-microscopic study of two cases. Acta Neuropathol 1982:56:151-156.

5. Sharma S, Sarkar C, Gaikwad S, Suri A, Sharma MC. Primary neurocytoma of the spinal cord: a case report and review of literature. J Neuro-Oncol 2005;74:47-52. 